\title{
Article \\ The Attractiveness of Five Common Mediterranean Weeds to Pollinators
}

\author{
Jane Morrison $^{1, *(\mathbb{D})}$, Jordi Izquierdo ${ }^{2} \mathbb{D}$, Eva Hernández Plaza ${ }^{3}\left(\mathbb{D}\right.$ and José L. González-Andújar ${ }^{3} \mathbb{D}$ \\ 1 Department of Environment and Geography, Bishop's University, Sherbrooke, QC J1M 1Z7, Canada \\ 2 Departament d'Enginyeria Agroalimentària i Biotecnologia, Universitat Politècnica de Catalunya, \\ Castelldefels, 08860 Barcelona, Spain; jordi.izquierdo@upc.edu \\ 3 Instituto de Agricultura Sostenible (CSIC), Campus Alameda del Obispo, 14004 Córdoba, Spain; \\ evahernandezplaza@gmail.com (E.H.P.); andujar@ias.csic.es (J.L.G.-A.) \\ * Correspondence: jmorriso@ubishops.ca
}

check for

updates

Citation: Morrison, J.; Izquierdo, J.; Hernández Plaza, E.;

González-Andújar, J.L. The

Attractiveness of Five Common

Mediterranean Weeds to Pollinators.

Agronomy 2021, 11, 1314. https://

doi.org/10.3390/agronomy11071314

Received: 17 May 2021

Accepted: 23 June 2021

Published: 28 June 2021

Publisher's Note: MDPI stays neutral with regard to jurisdictional claims in published maps and institutional affiliations.

Copyright: (c) 2021 by the authors. Licensee MDPI, Basel, Switzerland. This article is an open access article distributed under the terms and conditions of the Creative Commons Attribution (CC BY) license (https:// creativecommons.org/licenses/by/ $4.0 /)$.
Abstract: Concerns about a global decline in pollinators have called for more knowledge about the factors influencing wild pollinator abundance and diversity in agroecosystems. Agricultural intensification has been identified as the main cause of this "global pollinator crisis", particularly due to reductions in natural areas holding critical floral and nesting resources. Maintaining native wild plants in agricultural landscapes (e.g., in field margins) is often recommended as a cost-effective and efficient method for pollinator conservation. In this study, the role of common wild flowers, often considered weeds, in supporting pollinators in a Mediterranean agroecosystem was investigated. This work involved a two-year field trial to compare five native weed species common in Mediterranean cereal agroecosystems: Convolvulus arvensis L., Daucus carota L., Malva sylvestris L., Papaver rhoeas L., and Sonchus oleraceus L. The goal was to compare the attractiveness of these species, and a mixture of all five, to different flower-visiting insect groups in order to assess their value in supporting wild pollinators. Overall, D. carota had the highest number of insect visits, followed by P. rhoeas. C. arvensis, M. sylvestris, and S. oleraceus, which had lower numbers of visits. On the basis of their overall attractiveness to pollinators and low risk for invasiveness, D. carota, P. rhoeas, and M. sylvestris are the most likely to contribute positively to the conservation of pollinators in agroecosystems. Our results also suggest that it is advantageous for wild flowers sown for the purpose of pollinator conservation to be grown in clumps, rather than highly intermingled, for improved visitation rates.

Keywords: agroecosystems; biodiversity; ecosystem services; field margins; environmental management; pollinator conservation; sustainable agriculture; weed science

\section{Introduction}

In recent years, increasingly intensive agricultural practices have resulted in great concerns about a potential global decline in pollinators, both in terms of species richness and abundance [1]. Maintaining a diverse and abundant community of effective pollinators is crucial for sustaining native plant species diversity and the efficiency and stability of agricultural production [2]. The effects of the global decline in pollinators have already begun to be documented: a lower plant growth rate has been detected in highly pollinatordependent crops compared to non- or low-dependent crops [3].

The transformation of agricultural landscapes in the past half-century that has triggered this decline in bees and other pollinators [3] has involved the conversion of forests into fields and pastures [4], the expansion and amalgamation of pre-existing fields in order to enhance farming efficiency [5], and increased input of agricultural pesticides [6]. These changes have resulted in more homogeneous landscapes with a greater fragmentation of natural habitats. Agricultural pesticides negatively impact pollinator populations by further reducing foraging and habitat diversity, and they may have toxic effects [7]. 
Homogeneous landscapes can be enriched by encouraging the presence of native wild plant species [5]. Retaining a diversity of native wild flowers in agroecosystems is considered to be one strategy for curtailing the global decline of pollinators, as they are important hosts, providing continuous nesting and floral resources [8]. A diversity of wild flowers provides pollinators with a stable supply of pollen, nectar, and floral oils, notably when the main crop is not in bloom [9]. Because different insect species have different floral preferences, a season-long, high diversity of flowering plant species is required to support a high diversity of native pollinator species [3]. More detailed quantification of the role of native wild flowers in attracting pollinators could help enforce a new paradigm for agricultural management and biodiversity conservation.

Among the large number of species known as wild flowers, there is a specific set that is considered "weeds" by farmers - that is, species that tend to appear within fields provoking crop yield losses. These particular wild flowers have the reputation of being destructive in agriculture, and research typically focuses on the negative impacts of weeds and approaches to limit these impacts [10]. However, weeds are becoming more appreciated for their significant role in supporting biodiversity and ecosystem services [10,11]. Managing weeds with the specific goal of enhancing wild pollinator populations is currently largely based only on educated guesswork [3].

The general objective of this work is to further understand the role of weeds in agroecosystems and how they support pollinator abundance and diversity. To achieve this, five weed species common in Mediterranean agroecosystems with known attractiveness to wild pollinators were compared on the basis of the foraging rates of flower vising insects. The selected species were: Convolvulus arvensis L. (commonly known as field bindweed), Daucus carota L. (wild carrot or, in North America, Queen Anne's lace), Malva sylvestris L. (common mallow), Papaver rhoeas L. (common poppy or corn poppy), and Sonchus oleraceus L. (common sow thistle or annual sow thistle). These plant species are typically considered weeds, found frequently near cereal crops in the Iberian peninsula [12]. In this study, we examined the potential of each of these species and a mixture of all species to support pollinators by assessing: (a) the potential of each flower treatment to attract pollinators, (b) differences between treatments in terms of total pollinator visits, (c) differences between treatments in terms of their attraction to different taxonomic pollinator groups, and (d) whether flower species had more visits when grown in monocultures or mixed stands.

\section{Materials and Methods}

\subsection{Study Site and Experimental Design}

This experiment was carried out over two years, 2015 and 2016, at Agropolis, the research station of the School of Agriculture of the Universitat Politècnica de Catalunya. Agropolis is located in Viladecans $\left(41^{\circ} 17^{\prime} 24^{\prime \prime} \mathrm{N} 2^{\circ} 02^{\prime} 43^{\prime \prime} \mathrm{E}, 0\right.$ m.a.s.1.) in a flat, highly agricultural area. The mean monthly temperature was $16.7^{\circ} \mathrm{C}$ in 2015 and $16.8^{\circ} \mathrm{C}$ in 2016 . The total rainfall was $376 \mathrm{~mm}$ in 2015 and $456 \mathrm{~mm}$ in 2016 [13]. The landscape in a 1-km radius surrounding the experimental site was $45 \%$ arable lands and orchards, $20 \%$ pasture, and $35 \%$ urban and unproductive lands [14].

The experimental area comprised three blocks with a 2-m space between them. In each block were six plots $(2.5 \mathrm{~m} \times 2.5 \mathrm{~m})$ with a $1.5-\mathrm{m}$ space between them. Five plots were planted with a different species in monoculture and one plot was planted with a mixture of all five species randomly and equally distributed throughout the plot. The plots within each block were organized randomly such that each arrangement was unique and no two similar plots were located adjacent to one another.

\subsection{Weed Species Selection and Plot Preparation}

C. arvensis, D. carota, M. sylvestris, P. rhoeas, and S. oleraceus were selected based on observations carried out in a previous study [15] on the foraging activity of flower vising insects in cereal field margins in Catalonia. These five weed species were selected because they had the highest bee visits to plant occurrence ratios. 
In preparation for the first year of sampling, the seeds of the selected species were sown in a greenhouse in early 2015. When ready, seedlings were transplanted at the experimental site. For S. oleraceus, D. carota, and P. rhoeas, 64 plants were planted per plot (eight rows of eight plants). For M. sylvestris, only 32 plants were planted per plot (four rows of four plants) because of the large canopy and numerous flowers of each individual plant. C. arvensis was already an abundant species in this field and grew naturally in its designated plots. Mixed plots were made up of 13 plants of S. oleraceus, D. carota, and $P$. rhoeas; 6 plants of $M$. sylvestris; and approximately $20 \%$ of the plot was left with C. arvensis. A second round of transplanting replaced any seedlings that did not survive to maturity. At the end of the first season, the plots of annuals (S. oleraceus and P. rhoeas) were tilled by hand in order to incorporate the seeds and establish plots for the upcoming year. Biennials and perennials (D. carota and M. sylvestris) were trimmed down and preserved for the following year. $C$. arvensis was a prevalent weed with no need for manipulation in order to ensure its presence in the following year. In early 2016, more seeds of all planted species were sown in the greenhouse and later transplanted in order to supplement what had regrown from the previous year, filling any holes in the coverage.

All attempts were made to establish an even coverage in each plot. Ultimately, the number of open flowers was considered in the data analysis; thus, variations in the exact number of plants were accounted for. During both years, the site was irrigated one to two times per week and all undesirable plant species were removed regularly. Borders and walkways were cut down and sprayed with herbicide (Glyphosate 36\%) in order to avoid any external interference.

\subsection{Sampling Insect Visits}

Observations of insect visits to flowers were carried out twice a week on days when temperatures were at least $17^{\circ} \mathrm{C}$ with no rain [16]. Observations were conducted in the

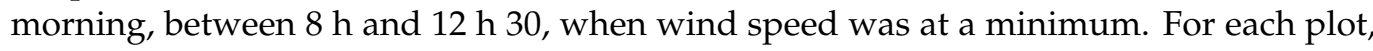
the sampling season began when there were at least five open flowers. For the mixed plots, sampling began when there were at least two species with five or more open flowers. Likewise, the sampling season ended when there were less than five open flowers per plot or, for the mixed plots, less than two species with five or more open flowers.

Sampling methodology was based on that of Barbir et al. [17]. On sampling days, the order in which the blocks were sampled alternated systematically. In each plot, first, the number of open flowers was counted. For D. carota, each inflorescence was considered one floral unit. Next, during a five minute period per plot, all insect visits were recorded in which the insect made direct contact with the reproductive organs of a flower (i.e., stamens and pistils). Insects were divided into the following groups: bees (order: Hymenoptera, clade: Anthophila), beetles (order: Coleoptera), hoverflies (order: Diptera, family: Syrphidae), butterflies and moths (order: Lepidoptera), true bugs (order: Hemiptera, suborder: Heteroptera), wasps (order: Hymenoptera, suborder: Apocrita), and other insects.

\subsection{Data Analysis}

At the end of each sampling season, the length of the flowering period, the average number of flowers, and the average number of insect visits were obtained for each plot. The flowering period was calculated as the number of days in which more than five flowers were in bloom in a single plot. The average number of flowers was obtained by dividing the total number of flowers recorded in each plot throughout the sampling season by the number of sampling days.

$$
\text { Average number of flowers }=\frac{\sum_{\text {plot }}^{\text {days }} \text { number of flowers }}{\text { number of sampling days }}
$$


The average number of insect visits was obtained by calculating the total number of insect visits recorded during the 5 min periods of each observation day for each plot during the sampling season, divided by the number of sampling days.

$$
\text { Average number of insect visits }=\frac{\sum_{\mathrm{plot}}^{\text {days }} \text { number of insect visits recorded }}{\text { number of sampling days }}
$$

We obtained both an average of all visiting insects (all taxonomic groups combined), as well as an average for bees only, beetles only, and all other insects groups combined (due to their overall low number of visits). In addition, in the mixed plots, the average number of insect visits and the average number of flowers were also obtained separately for each of the flower species. All analyses were carried out in R 3.6.3 for Linux [18].

\subsubsection{Potential of Flower Treatment to Attract Pollinators}

Differences between treatments (all species in monoculture and the mixed plots) in the length of the flowering period and the average number of flowers were analyzed using general mixed-effects models using functions from the package lme4 [19]. Treatment, year, and their interaction were included as fixed factors, and the block was included as a random factor. Although we were interested in the main effect of flower treatment, an interaction term with the year was included because inter-annual variation in precipitation and temperature in Mediterranean climates can largely determine the response of vegetation and the associated taxa. Additionally, we preferred to include the year as a fixed factor and not as a random factor because having a random factor with only two levels (two years) can lead to problems in the model (lack of model convergence in our case). The overall importance of fixed effects was assessed by a type III Wald test using a chi-square statistic in the library package car [20]. Marginal and conditional $\mathrm{R}^{2}$ were computed using functions from the MuMIn library [21] to obtain the variability explained by the fixed factors and the whole model, respectively [22]. Model assumptions were graphically assessed using functions from the package ggResidpanel [23]. Post hoc comparisons were computed using functions from the emmeans package [24].

\subsubsection{Insect Visits to Flower Treatments}

Total Pollinator Visits

Differences between treatments in the average number of pollinator visits (all insect groups combined) were analyzed using general linear mixed models as explained above. Treatment, year, and their interaction were included as fixed effects. The average number of flowers for each plot was also included as a covariate to account for differences between plots in terms of the availability of flowers for insects to visit. Block was included as a random factor.

\section{Visits by Taxonomic Group}

A general mixed-effects model was also used to analyze whether treatments differed in their attraction to the pollinator groups (bees, beetles, and the rest of the groups together) following the procedure described above. The model was similar to the one used to analyze the total number of pollinator visits, but in this case, the taxonomic group and its interaction with the treatment and the triple interaction between the year, treatment, and taxonomic group were also included as a fixed factors.

Pollinator Visits to Flowers Growing in Monocultures vs. Flowers Growing in Mixed Treatments

Finally, we also tested whether flower species had more visits when growing in monocultures or mixed stands. To accomplish this, we first obtained the average number of insect visits in the mixed plots separately for each flower species. Then, a general mixed-effects model was used with the flower treatment, growing treatment (monoculture 
vs. mixed stands), year, and the interactions between the growing treatment and flower treatment as well as the growing treatment and year as fixed factors. The average number of flowers was also included as a covariate. In this case, the number of flowers in the mixed plots was computed separately for each flower species. Block was included as a random factor.

\section{Results}

\subsection{Insect Visits to the Experimental Site}

In total, 4770 insects were observed foraging on experimental flowers in 2015, and 4289 insects were observed in 2016 (Figure 1). In 2015, the greatest number of observed visits was by bees (2913 visits), then beetles (1110), hoverflies (435), true bugs (115), other insects (78), butterflies and moths (63), and wasps (56). In 2016, the most frequently observed flower visitors were beetles (2172 visits), then bees (1194), true bugs (788), other insects (96), hoverflies (16), wasps (14), and butterflies and moths (9).

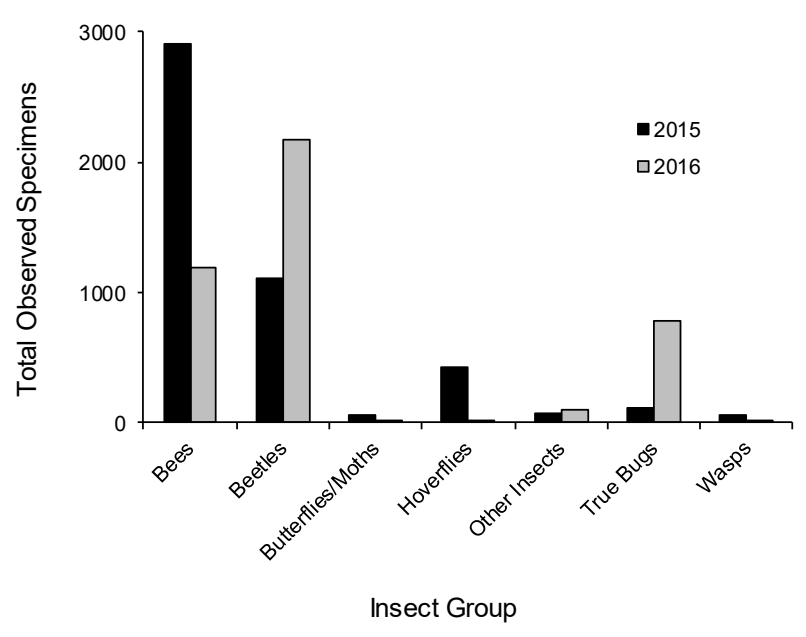

Figure 1. Total observed specimens of each insect group per year.

Of the true bugs observed, in 2015, 65\% were Oxycarenus lavaterae (family: Lygaeidae), $32 \%$ were larger true bugs from the families Lygaeidae or Pyrrhocoridae, likely Lygaeus equestris or Scantius aegyptius, and 3\% were other species. In 2016, 96\% were O. lavaterae and $4 \%$ were from the families Lygaeidae or Pyrrhocoridae. (Refer to Supplemental Material, Section 1.1, for more details about insect identification using pan traps.)

\subsection{Potential of Flower Treatment to Attract Pollinators}

Flower species varied in the length of the flowering period and the average number of flowers, but the differences depended on the year (as shown by year and treatment interactions; flowering period: chi-square $=67.8, \mathrm{df}=5, p<0.001$; number of flowers: chi-square $=18.7 . \mathrm{df}=5, p=0.002$; Supplemental Material-Tables S1 and S2). Regarding the flowering period, the interaction was mainly driven by an increase in the length of the flowering period in M. sylvestris and S. oleraceus plots in 2016 with respect to 2015. In both years, $C$. arvensis and mixed plots had the longest flowering periods, whereas $S$. oleraceus and P. rhoeas plots had the shortest. M. sylvestris and D. carota plots had flowering periods of intermediate length (Figure 2). As for the number of flowers, the interaction was mostly due to an increase in the values for $M$. sylvestris plots and a decrease in $P$. rhoeas plots in 2016 with respect to 2015. In 2015, C. arvensis and D. carota plots had the highest number of flowers and M. sylvestris and S. oleraceus plots had the lowest, whereas $P$. rhoeas and mixed plots were intermediate in their values. In 2016, C. arvensis had the highest number of flowers, $P$. rhoeas and S. oleraceus the lowest, and the rest of the flower treatments had intermediate values (Figure 3). Fixed factors in the models accounted for $94 \%$ and $61 \%$ of the variability encountered in the length of the flowering period and the 
number of flowers, respectively ( $R^{2}$ marginal). Block explained an additional $5 \%$ of the variability for the number of flowers but had a negligible effect on the flowering period $\left(R^{2}\right.$ conditional- $\mathrm{R}^{2}$ marginal).

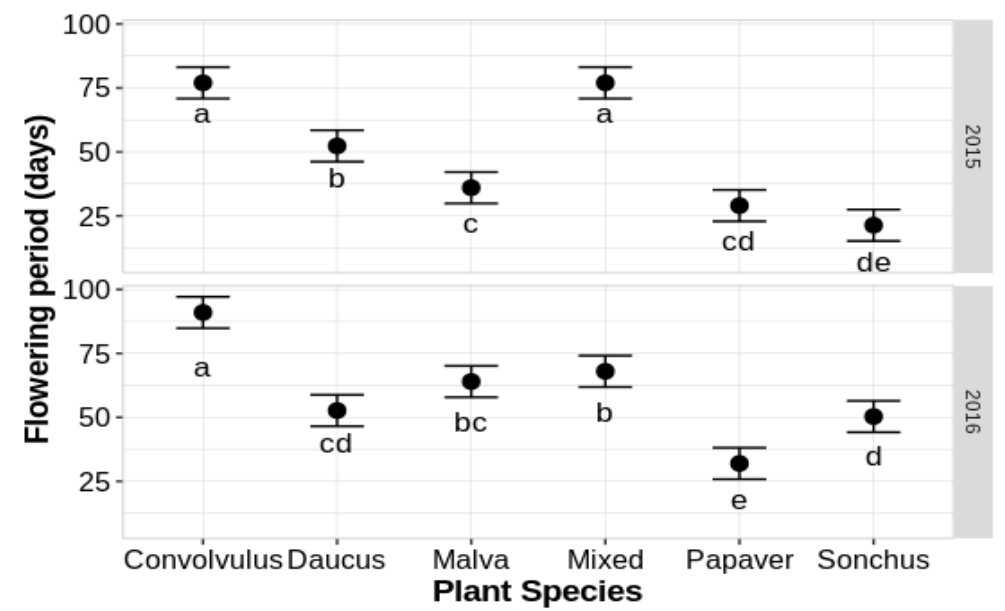

Figure 2. Differences in the lengths of the flowering periods between flower treatments in both years of the study (2015 and 2016). Values are the estimated marginal means from the general mixed-effects model. Bars show confidence intervals at the 0.95 level. Letters indicate differences between treatments derived from post hoc pairwise comparisons using the Tukey method for $p$-value adjustment. Contrasts were performed between treatments and for each year separately. Flower species are indicated by genus.

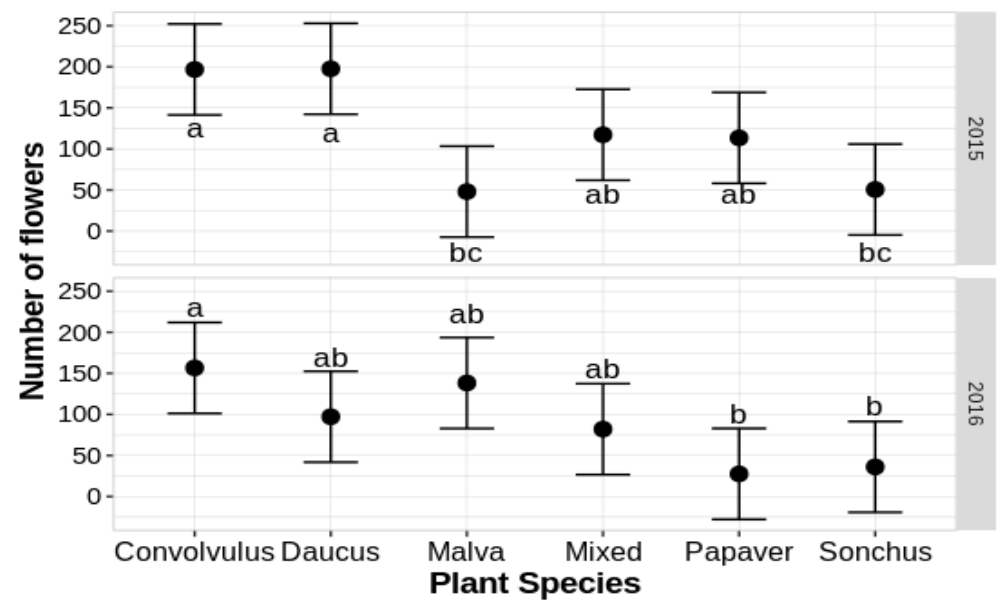

Figure 3. Differences between treatments in the average number of flowers in both years of the study (2015 and 2016). Values are the estimated marginal means from the general mixed-effects model. Bars show confidence intervals at the 0.95 level. Letters indicate differences between treatments derived from post hoc pairwise comparisons using the Tukey method for $p$-value adjustment. Contrasts were performed between treatments and for each year separately. Flower species are indicated by genus.

\subsection{Insect Visits to Flower Treatments}

\subsubsection{Total Pollinator Visits}

Treatments differed in the average number of insect visits, and the effect was dependent on the year (year $\times$ treatment interaction: chi-square $=73.1, \mathrm{df}=5, p<0.001$; Table 1 , Figure 4). The interaction was due to a decrease in the number of visits recorded in $P$. rhoeas plots in 2016. Overall, across both years, D. carota plots had the highest number of insect visits, followed by $P$. rhoeas and then mixed plots. C. arvensis, M. sylvestris, and $S$. oleraceus had lower numbers of visits. In 2015, P. rhoeas plots had a number of visits similar to that of D. carota plots, but in 2016, the average number of visits recorded in the P. rhoeas 
treatment was much lower and similar to the other treatments. The model also showed a slight positive effect of the number of flowers on the visitation of insects to the plots (number of flowers $=0.027 \pm 0.016$; chi-square $=2.9, \mathrm{df}=1, p=0.09$; Table 1 ). Fixed factors in the model accounted for $94 \%$ of the variability encountered in the response variable $\left(R^{2}\right.$ marginal), with block explaining less than $1 \%$ of the variability.

Table 1. Effects of flower treatment, year, their interaction, and the average number of flowers on the average number of pollinator visits to the plots. Chi-square values and degrees of freedom (df) were derived via a general linear mixed model.

\begin{tabular}{cccc}
\hline & Chi-Square & df & $p$ \\
\hline Intercept & 5.1 & 1 & $<0.001$ \\
Flower treatment & 233.8 & 5 & $<0.001$ \\
Year & 0.09 & 1 & 0.03 \\
Number of flowers & 2.91 & 1 & 0.09 \\
Treatment $\times$ Year & 73.1 & 5 & $<0.001$ \\
\hline
\end{tabular}

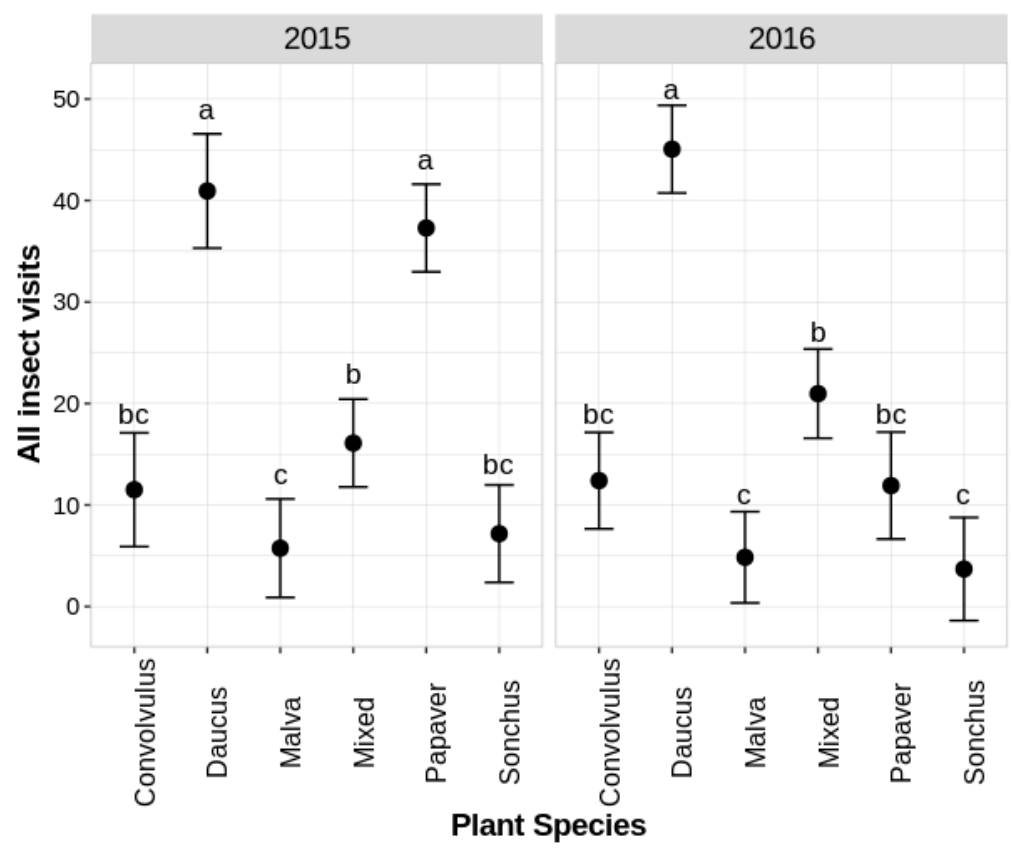

Figure 4. Differences in the average number of insect visits per five-minute period to the flower treatments in both years of the study (2015 and 2016). Values are the estimated marginal means from the general mixed-effects model accounting for the number of flowers in the plots. Bars show confidence intervals at the 0.95 level. Letters indicate differences between treatments derived from post hoc pairwise comparisons using the Tukey method for $p$-value adjustment (at $p<0.05$ ). Contrasts were performed between treatments and for each year separately. Flower species are indicated by genus.

\subsubsection{Visits by Taxonomic Group}

Treatments differed in the number of visits received from bees, beetles, and the rest of the taxonomic groups, and this response was also affected by the year (treatment by taxonomic group by year interaction Table 2; Figure 5). To explore the significance of the interaction, we used Tukey's contrasts (a) between flower treatments within years and insect taxonomic groups and (b) between insect taxonomic groups within years and flower treatments. Contrasts between flower treatments showed the relevance of $D$. carota for all insect groups and P. rhoeas for bees (Figure 5). P. rhoeas and D. carota had a higher number of bee visits for both years, with the other flower treatments ranking slightly differently across the years. Regarding beetles, D. carota plots received a higher number of visits 
than the other treatments in both years. For the other insect groups combined, $D$. carota in 2015, together with the mixed treatment in 2016, registered more visits than the other treatments. Additionally, contrasts between insect groups-within flower treatments and years - showed that in 2015, bees represented the majority of the insect visits to plots, except in the case of $D$. carota and M. sylvestris plots, which received a similar number of visits from the three insect groups. In 2016, beetles surpassed or equalled the number of bee visits in some treatments. D. carota plots had more visits by beetles than by the other two groups, $C$. arvensis plots had more visits from beetles and bees than from the other insect groups combined, and the mixed plots registered more visits from beetles and other insect groups than from bees. On the contrary, M. sylvestris and S. oleraceus had a low number of visits from all three insect groups, and $P$. rhoeas had more visits from bees. Fixed factors in the model accounted for $93 \%$ of the variability encountered in the response variable $\left(R^{2}\right.$ marginal), with block explaining less than $1 \%$ of the variability.

Table 2. Effects of flower treatment, year, taxonomic group, their interactions, and the average number of flowers on the average number of pollinator visits to the plots. Chi-square values and degrees of freedom (df) were derived via a general linear mixed model.

\begin{tabular}{cccc}
\hline & Chi-Square & df & $p$ \\
\hline Intercept & 17.8 & 1 & $<0.001$ \\
Flower treatment & 473.5 & 5 & $<0.001$ \\
Year & 4.24 & 1 & 0.04 \\
Number of flowers & 2.93 & 1 & 0.09 \\
Taxonomic group & 16.76 & 2 & $<0.001$ \\
Treatment $\times$ Year & 148.33 & 5 & $<0.001$ \\
Treatment $\times$ Taxonomic group & 344.5 & 10 & $<0.001$ \\
Year $\times$ Taxonomic group & 13.5 & 2 & 0.001 \\
Treatment $\times$ Year $\times$ Taxonomic group & 141.5 & 10 & $<0.001$ \\
\hline
\end{tabular}

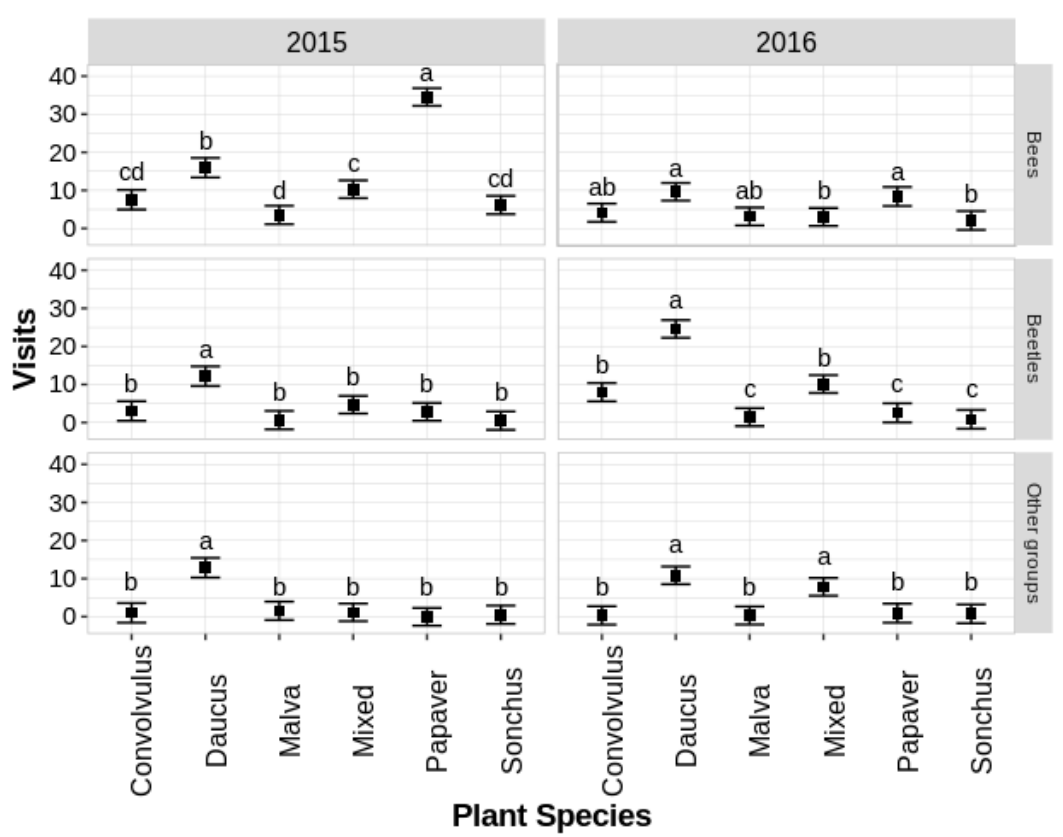

Figure 5. Differences in the average number of visits from bees, beetles, and other insect groups to the flower treatments in both years of the study (2015 and 2016). Values are the estimated marginal means from the general mixed-effects model accounting for the number of flowers in the plots. Bars show confidence intervals at the 0.95 level. Letters indicate differences between treatments for a given year and insect taxonomic group derived from post hoc pairwise comparisons using the Tukey method for $p$-value adjustment (at $p<0.05$ ). Flower species are indicated by genus. 
3.3.3. Pollinator Visits to Flowers Growing in Monocultures vs. Flowers Growing in Mixed Treatments

Flowers growing in monocultures received more visits than those growing in the mixed stands, but the difference depended on the flower species (as shown by growing treatment $\times$ flower treatment: chi-square $=98.5, \mathrm{df}=4, p<0.001$; Table 3, Figure 6). Tukey contrasts, performed separately for each species, showed that for S. oleraceus and $M$. sylvestris, the number of visits was quite similar across growing treatments, whereas the other flower species received a higher number of visits in monoculture plots. This effect was similar across both years (growing treatment $\times$ year: chi-square $=3.6, \mathrm{df}=1, p=0.06$; Table 3). A higher number of flowers was positively related to a higher number of insect visits (chi-square $=7.9, \mathrm{df}=1, p=0.005$; Table 3 ). Fixed factors in the model accounted for $89 \%$ of the variability encountered in the response variable ( $R^{2}$ marginal), with block explaining less than $1 \%$ of the variability.

Table 3. Effects of growing treatment (monoculture vs. mixed), flower treatment, year, interactions between growing treatment and flower treatment as well as growing treatment and year, and the average number of flowers on the average number of pollinator visits to the plots. Chi-square values and degrees of freedom ( $\mathrm{df}$ ) were derived via a general linear mixed model.

\begin{tabular}{cccc}
\hline & Chi-Square & df & $p$ \\
\hline Intercept & 0.18 & 1 & 0.67 \\
Growing treatment & 7.3 & 1 & 0.007 \\
Flower treatment & 2.7 & 4 & 0.61 \\
Year & 0.02 & 1 & 0.89 \\
Number of flowers & 7.9 & 1 & 0.09 \\
Growing treatment $\times$ Flower treatment & 98.5 & 4 & $<0.001$ \\
Growing treatment $\times$ Year & 3.6 & 1 & 0.06 \\
\hline
\end{tabular}

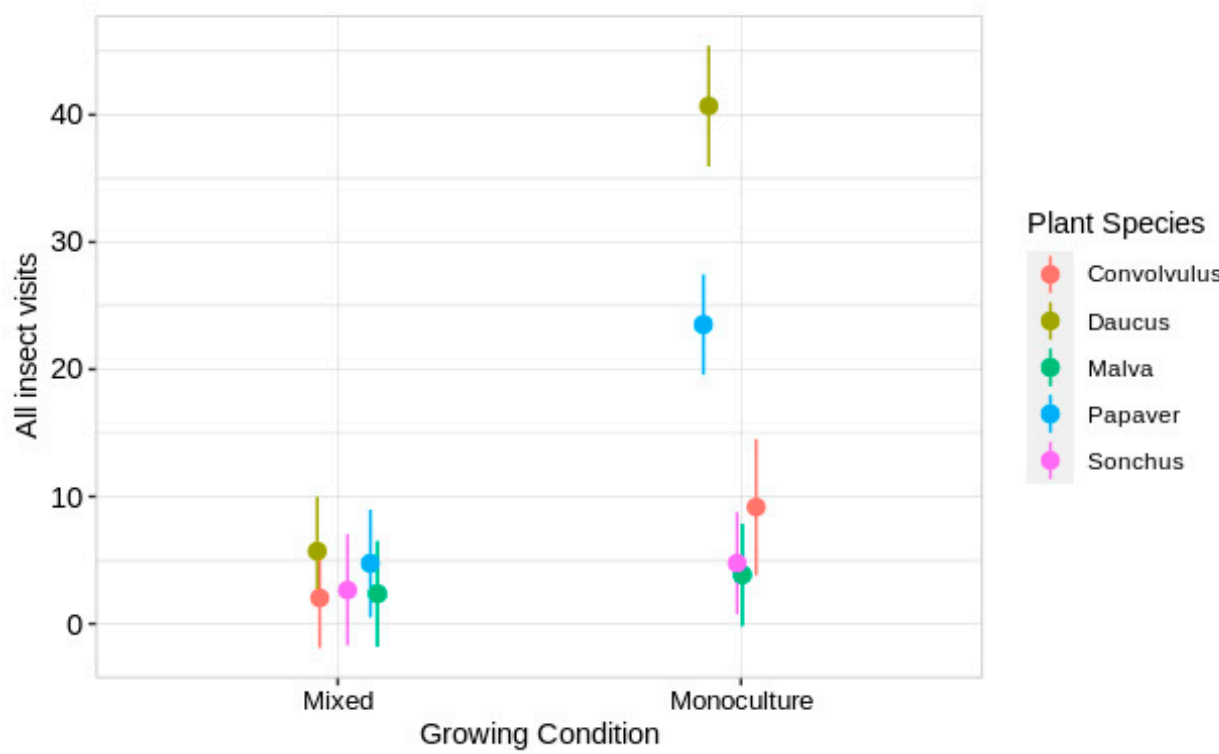

Figure 6. Differences in the average number of insect visits when plants were grown in monocultures vs. mixed plots. Values are the estimated marginal means from the general mixed-effects model accounting for the number of flowers in the plots. Bars show confidence intervals at the 0.95 level. Flower species are indicated by genus.

\section{Discussion}

\subsection{Visits to Flower Species}

In the following sections, we examine the potential of each flower species to support pollinators in agroecosystems. 


\subsubsection{D. carota}

Relative to the other flowers, $D$. carota had a moderate flowering period and a high number of insect visits. There were many visits from bees and beetles to D. carota, as well as a relatively high number of visits from other groups of pollinators. D. carota was found to attract a great diversity of insect visitors, having visits from all insect groups in both years, except butterflies and moths. Our results are in agreement with several studies, which all observed a wide taxonomical range of insect visitors to D. carota [25-27].

The high number of insect visits to $D$. carota could be due to a number of reasons. First, unlike all the other species, the floral nectaries of D. carota are fully exposed [28], and the open accessible inflorescences facilitate contact from any suitably sized insect [29]. Westmoreland and Muntan [30] suggested that flies and beetles are attracted to the plant's slightly pungent scent. These factors may explain why D. carota had a high number of insect visits compared to the other species and a wide variety of visitors.

The seeds of $D$. carota can reportedly persist in the soil seed bank for two to five years [31], and seedlings can emerge and survive in several types of ground cover, including thick vegetation [32]. D. carota is not usually considered a high priority for management efforts. Nevertheless, it can be persistent and require more active management in soils with a high clay content [32]. Eckardt [32] also claimed that it is a threat to recovering grasslands and prairies because it matures faster and grows taller than many of the native species.

In summary, based on its overall attractiveness to a wide range of pollinators, nonpriority status as a weed, and moderately long flowering period, D. carota is likely to contribute positively to pollinators in agroecosystems.

\subsubsection{P. rhoeas}

In general, relative to the other flower species, $P$. rhoeas had a high number of insect visits but a shorter flowering period. For both years, the main visitors to $P$. rhoeas were bees, followed distantly by beetles. Almost no other insects visited, except for other insects in 2016. A scientific review of $P$. rhoeas is in agreement with our results, stating that solitary bees are indeed particularly frequent visitors of $P$. rhoeas [33].

The flowers of $P$. rhoeas have petals larger than any of the other studied species, the inside of the flower is very open, and the anthers are very easy to access. The flowers of $P$. rhoeas hold a large amount of pollen and very little or no nectar [34,35]. Thus, insect visits to $P$. rhoeas are motivated only by pollen collection. The narrow spectra of visitors to $P$. rhoeas (only bees, beetles, and other insects) is likely due to this fact. For insects seeking primarily pollen (e.g., wild bees [36]), P. rhoeas is an attractive choice.

In various countries, $P$. rhoeas has been presented as a problematic weed for crops. In Spain, it is reported as a principal weed of barley and wheat [37] and its seeds can lie dormant in the soil for over 80 years [38]. However, P. rhoeas is not considered an invasive weed-its seeds remain close to the mother plant, and the probability of them spreading from the edge of the field is low. Furthermore, the "Plantwise Knowledge Bank" [39] classifies $P$. rhoeas as only moderately competitive against wheat and reported that biomass and seed production were significantly reduced by increasing crop densities.

In summary, although it has a short flowering period, because of its high attractiveness to bees and low invasiveness, $P$. rhoeas has the potential to contribute positively to pollinator conservation in agroecosystems.

\subsubsection{M. sylvestris}

In comparison to the other flower species, $M$. sylvestris had a moderate flowering period and a low number of insect visits. The most frequent visitors to $M$. sylvestris were bees in both years. All other insect groups visited during at least one of the years, although very infrequently. Overall low attractiveness of $M$. sylvestris to flower-visiting insects was also observed in other studies [40-42]. M. sylvestris has large corollas (the second largest amongst the studied species), although the nectar is concealed [43]. 
Gorenflo et al. [44], in Germany, also found bees to be the main visitor of M. sylvestris, comprising $98 \%$ of all insect visits. However, Gorenflo et al. observed much higher visitation frequencies from honeybees than from bumblebees or Halictidae bees. In our study, we observed mostly Halictidae bees and very few honeybees (see Supplemental Material, Section 1.1.2). These findings suggest that honeybees are avid visitors to $M$. sylvestris, and thus the comparably low visits from bees in this experiment may be at least partially due to the sparsity of foraging honeybees at the study site.

Many authors refer to $M$. sylvestris as a weed due to its widespread and persistent root system, and it can be invasive in food crops [45]. However, Dutoit et al. [46] did not find it to be invasive in cereal crops.

In summary, M. sylvestris was only seen to be moderately attractive to most pollinators, and it could be a problematic weed in some environments. However, in the right context, $M$. sylvestris could be a positive addition to agricultural landscapes for pollinator conservation because it is perennial and exhibited a moderately long flowering period.

\subsubsection{C. arvensis}

In general, relative to the other flower species, $C$. arvensis had a relatively low number of insect visits but a very long flowering period. The main insects visiting $C$. arvensis were bees and beetles. These results were slightly less favourable than another study (albeit located in Canada), which considered C. arvensis to be intermediate in terms of pollinator visitation rates compared to other wild flower species [47]. One reason why this species may not be particularly attractive to pollinators is that the nectar in their flowers is concealed [43].

Waddington [48] observed Halictid bees foraging at dense arrays of $C$. arvensis flowers (ranging from approximately $40-225$ flowers $/ \mathrm{m}^{2}$ ) and found that bee numbers increased linearly with flower density. In our study, $C$. arvensis coverage was relatively dense (mean $=197$ flowers $/ \mathrm{m}^{2}$ in 2015 and mean $=112$ flowers $/ \mathrm{m}^{2}$ in 2016); nevertheless, bee visits (which were mostly from the family Halictidae) were low compared to the other flower species. The greater flower density in 2015 may partially explain why there were more bees in that year.

C. arvensis is often considered to be a serious weed. Although C. arvensis is a relatively poor competitor for light, it competes effectively for soil moisture because of its extensive root system [49]. Its underground network of roots is said to reduce crop yields and interfere with harvesting operations [50] and allows the plant to persist after disturbances [49]. Seeds can remain viable in the soil for up to two decades [51]. Furthermore, it has been known to climb and knock over crop plants [52].

In summary, C. arvensis had a long flowering period, but is difficult to control, and exhibited mostly low attractiveness to flower visitors. Based on this study, C. arvensis does not appear to provide great value for pollinators in agroecosystems.

\subsubsection{S. oleraceus}

Compared to the other flower species, S. oleraceus had a short flowering period and a low number of insect visits. The only visitors to $S$. oleraceus were bees and beetles, and in 2015, only bees visited. The biggest downfall of S. oleraceus was the fact that the flowers were only open for a short period each day. This short daily period of bloom, also noted by Lewin [53] and Percival [54], greatly reduced its efficiency in attracting flower-visiting insects.

S. oleraceus may be invasive and has the potential to compete with cultivated plant species [55]. According to the US Forest Service [56], it is considered to be invasive in several countries. Weber [57] claims that its large stature and high nutrient uptake could cause soil impoverishment in heavily infested sites. On the other hand, it is not known to significantly invade high-quality natural areas and does not regenerate from root fragments and can thus be managed by cutting or mowing [57]. 
In summary, because of its very limited periods of daily bloom, low flowering period, and low attractiveness for all pollinator groups, these results do not indicate that $S$. oleraceus would be of particular benefit to agroecosystems for the purpose of supporting pollinators.

\subsection{Monocultures vs. Mixed Stands}

There was a high frequency of visits from bees and beetles to mixed plots, and in 2016 only, true bugs as well. In general, floral mixtures have the advantage of longer overall flowering periods and more functional diversity than a species in a monoculture.

Most of the flower species (except $S$. oleraceus and $M$. sylvestris) received more visits when growing in monocultures than in mixed stands. In a similar experiment by Barbir et al. [17], the same phenomenon was witnessed, in which higher visits were recorded in monocultures compared to mixed plots. As hypothesized by Barbir et al., the lower visitation rate to mixed plots could be a result of the lower floral density of each individual species, causing the probability that insects will see specific flowers from a distance to be lower. It is also more complicated for insects to travel from one plant to another, and visual or scent cues could be intercepted. For example, it is known that growing different crops in the same field, compared to growing them in monocultures, reduces the incidence of pests [58].

In summary, based on these results, it could be recommended that wild flowers sown for the conservation of pollinators should be arranged in clumps, rather than highly intermingled.

\subsection{Implications of Pan Trap Results}

Bees are usually considered the most important group of pollinators. When considering bee visits in our study, the high proportion of bees from the family Halictidae (95\% of bee specimens) must be taken into consideration, as well as the low proportions of honeybees $(2 \%)$ and bumblebees $(0 \%)$. Bees from the genus Halictus are sometimes limited by their short tongues, which prevent them from extracting resources from flowers with deep corollas [59]. This is congruent with observations from our study, in which bees preferred $P$. rhoeas, which has an open, bowl-shaped corolla and is known to be pollinated by short-tongued bees [43]. D. carota, which has exposed nectaries and open accessible inflorescences [28,29], was also frequently visited by the bees.

Beetles are important pollinators due to their sheer abundance [60]. However, they often feed on floral tissue and in some cases can cause damage to plants and be considered pests [61]. Of the beetles observed, several were from the family Dermestidae, genus Orphilus (52\% in 2015 and 34\% in 2016). These beetles are not categorized in the literature as pests. There were also a significant number of small beetles from the family Mordellidae (34\% in 2015 and 22\% in 2016). These adults feed on the pollen of many different plants, especially from the families Apiaceae (such as D. carota) and Asteraceae (such as S. oleraceus) [62]. In our study, many mordellids were found on D. carota, but not on S. oleraceus. No claims were found in the literature suggesting that beetles from the Mordellidae family could be agricultural pests. Long and slender beetles from the families Cerambycidae, Meloidae, or Cantharidae were also observed in relatively high numbers $(12 \%$ combined in 2015 and 9\% in 2016). All three of these families commonly visit flowers, although their short tongues limit them to feed mostly from flowers with freely exposed nectaries [63], which could explain their attraction to D. carota in this study. The larvae of Cantharidae species are predators of soft-bodied insects, feeding on caterpillars and locust eggs, and can potentially reduce the impact of certain pests on crops [59]. Overall, no beetles frequently observed in this study were of any great concern as pests.

Although usually not considered to be significant pollinators, true bugs are common flower visitors with potential ecological significance [64]. Some species are known to be predators of other pest species and can be used to control soft-bodied insects, for example, aphids and caterpillars [65]. On the other hand, because most true bugs feed on plants, some species can be serious pests to cultivated crops [66]. The majority of the true bugs 
observed in this study belonged to the species O. lavaterae (65\% in 2015 and $96 \%$ in 2016). O. lavaterae is widespread throughout Europe [67], feeds on plants, and is trophically associated with the plant family Malvaceae, including M. sylvestris [68], as was observed in this study. It is not considered to be a pest [67]. Several larger true bugs from the families Lygaeidae or Pyrrhocoridae were also observed, likely Lygaeus equestris or Scantius aegyptius (32\% in 2015 and $4 \%$ in 2016). L. equestris is a seed predator that feeds on a number of plant species and could be a pest of commercial seed crops [69]. S. aegyptius is not considered a plant pest and, according to Bryant [70], does not appear to pose any serious threats to agriculture or the environment. (Refer to Supplemental Material, Section 1.1, for the methodology and results of the insect identification using pan traps.)4.4. Implications for Management.

Wild plant diversity can be easily maintained in agroecosystems by setting aside field margins and protecting them from pesticides, fertilizers, and disturbances. One common concern for farmers is that margins left to regenerate naturally may encourage pernicious weeds, which can spread into the crop and be difficult to control [4]. Marshall [71] claims that the perception weeds in field margins will invade crops is misguided and that the number of important weed species that originate in margins is limited. Nevertheless, Marshall further noted that when winter annuals dominate the boundary flora, as is typical in Mediterranean conditions, margins may have a more significant influence on the presence of weed flora. In these circumstances, specialized margin management strategies should be applied, for example, by sowing non-invasive perennial species to help provide a barrier against the spread of weeds from the field edge into the crops [4].

\subsection{Study Limitations and Suggestions for Future Research}

It is possible that because this was a research trial and plants were concentrated in a common area, the results could vary from what may actually occur when plants exist in field margins or are distributed throughout the landscape of a farm. Because the same plant species sampled within a site and year can receive very different groups of visitors [34], the results from this work may not be observed in different contexts or different years.

During the literature review for this study, it was observed that the information available about specific wild plant species (i.e., traits, attractiveness to pollinators, and weediness) is limited and extremely out of date. New research is needed on the ecosystem services provided by individual wild plant species. It is recommended that more studies be conducted examining a wide range of wild plant species and their potential contributions to agroecosystems. Research is also required on the viability of different non-invasive wild plant species to be sown in specific regions and varying conditions.

It is clear that participation in sustainable agriculture requires changes in economic frameworks, including fair markets and prices, and governmental incentives [72]. For example, farmers could be compensated for losses in income which may arise as a result of adopting strategies for maintaining biodiversity [5]. The hope is that this work will help lead the way for the development of realistic management strategies sensitive to the realities of farmers for efficient and environmentally sustainable farming, shifting agricultural paradigms to create more robust agroecosystems.

\section{Conclusions}

- $\quad$ Overall, D. carota had the highest number of insect visits, followed by P. rhoeas. C. arvensis, $M$. sylvestris, and $S$. oleraceus, which had lower numbers of visits.

- D. carota, P. rhoeas, and M. sylvestris were found to be the most likely to support pollinators in agroecosystems. C. arvensis and S. oleraceus were found to be less likely to contribute to pollinator conservation.

- It is recommended that wild flowers sown for the conservation of pollinators be arranged in clumps, rather than highly intermingled, in order to improve visitation rates.

- Wild plants are important aspects of sustainable farms, helping to maintain biodiversity and ecosystem functioning, and should be promoted in order to dispel 
common misconceptions and encourage their acceptance. Continued effort is needed to translate science to policy and engage with farmers to incorporate new strategies by providing them with financial and logistical support.

Supplementary Materials: The following are available online at https://www.mdpi.com/article/10 .3390/agronomy11071314/s1, Insect identification with traps; Table S1. Effects of flower treatment, year, and their interaction on the length of the flowering period; Table S2. Effects of flower treatment, year, and their interaction on the average number of flowers in the plots.

Author Contributions: Conceptualization and methodology, J.M., J.I., and J.L.G.-A.; formal analysis, J.M. and E.H.P.; investigation, J.M. and J.I.; writing-original draft preparation, J.M. and E.H.P.; writing-review and editing, J.M., J.I., E.H.P., and J.L.G.-A.; supervision, J.I. and J.L.G.-A. All authors have read and agreed to the published version of the manuscript.

Funding: This work was supported by FEDER (European Regional Development Funds) and the Spanish Ministry of Economy and Competitiveness (projects AGL2012-33736 and AGL2015-64130-R). The Natural Sciences and Engineering Research Council of Canada (NSERC) provided J.M. with a doctoral scholarship.

Data Availability Statement: The data presented in this study are available on request from the corresponding author.

Conflicts of Interest: The authors declare no conflict of interest. The funders had no role in the design of the study; in the collection, analyses, or interpretation of data; in the writing of the manuscript; or in the decision to publish the results.

\section{References}

1. Nielsen, A.; Steffan-Dewenter, I.; Westphal, C.; Messinger, O.; Potts, S.G.; Roberts, S.P.M.; Settele, J.; Szentgyörgyi, H.; Vaissière, B.E.; Vaitis, M.; et al. Assessing bee species richness in two Mediterranean communities: Importance of habitat type and sampling techniques. Ecol. Res. 2011, 26, 969-983. [CrossRef]

2. Balzan, M.V.; Bocci, G.; Moonen, A.C. Augmenting flower trait diversity in wildflower strips to optimise the conservation of arthropod functional groups for multiple agroecosystem services. J. Insect Conserv. 2014, 18, 713-728. [CrossRef]

3. Nicholls, C.I.; Altieri, M.A. Plant biodiversity enhances bees and other insect pollinators in agroecosystems. A review. Agron. Sustain. Dev. 2013, 33, 257-274. [CrossRef]

4. Marshall, E.J.P.; Moonen, A.C. Field margins in northern Europe: Their functions and interactions with agriculture. Agric. Ecosyst. Environ. 2002, 89, 5-21. [CrossRef]

5. Tscharntke, T.; Klein, A.M.; Kruess, A.; Steffan-Dewenter, I.; Thies, C. Landscape perspectives on agricultural intensification and biodiversity-Ecosystem service management. Ecol. Lett. 2005, 8, 857-874. [CrossRef]

6. Brittain, C.A.; Vighi, M.; Bommarco, R.; Settele, J.; Potts, S.G. Impacts of a pesticide on pollinator species richness at different spatial scales. Basic Appl. Ecol. 2010, 11, 106-115. [CrossRef]

7. Sponsler, D.B.; Grozinger, C.M.; Hitaj, C.; Rundlöf, M.; Botías, C.; Code, A.; Lonsdorf, E.V.; Melathopoulos, A.P.; Smith, D.J.; Suryanarayanan, S.; et al. Pesticides and pollinators: A socioecological synthesis. Sci. Total Environ. 2019, 662, 1012-1027. [CrossRef]

8. Legere, A.; Stevenson, F.C.; Benoit, D.L. Diversity and assembly of weed communities: Contrasting responses across cropping systems. Weed Res. 2005, 45, 303-315. [CrossRef]

9. Hannon, L.E.; Sisk, T.D. Hedgerows in an agri-natural landscape: Potential habitat value for native bees. Biol. Conserv. 2009, 142, 2140-2154. [CrossRef]

10. Blaix, C.; Moonen, A.C.; Dostatny, D.F.; Izquierdo, J.; Le Corff, J.; Morrison, J.; Von Redwitz, C.; Schumacher, M.; Westerman, P.R. Quantification of regulating ecosystem services provided by weeds in annual cropping systems using a systematic map approach. Weed Res. 2018, 58, 151-164. [CrossRef]

11. Marshall, E.J.P.; Brown, V.K.; Boatman, N.D.; Lutman, P.J.W.; Squire, G.R.; Ward, L.K. The role of weeds in supporting biological diversity within crop fields. Weed Res. 2003, 43, 77-89. [CrossRef]

12. Gonzalez-Andujar, J.; Saavedra, M. Spatial distribution of annual grass weed populations in winter cereals. Crop Prot. 2003, 22, 629-633. [CrossRef]

13. Ruralcat Meteorological Data. Available online: www.ruralcat.gencat.cat (accessed on 21 June 2021).

14. Sistema de Información Geográfica de Parcelas Agrícolas. Available online: http://sigpac.mapa.es/fega/visor/ (accessed on 1 September 2014).

15. Morrison, J.; Izquierdo, J.; Plaza, E.H.; González-Andújar, J.L. The role of field margins in supporting wild bees in Mediterranean cereal agroecosystems: Which biotic and abiotic factors are important? Agric. Ecosyst. Environ. 2017, 247, 216-224. [CrossRef] 
16. Pywell, R.F.; Warman, E.A.; Carvell, C.; Sparks, T.H.; Dicks, L.V.; Bennett, D.; Wright, A.; Critchley, C.N.R.; Sherwood, A. Providing foraging resources for bumblebees in intensively farmed landscapes. Biol. Conserv. 2005, 121, 479-494. [CrossRef]

17. Barbir, J.; Badenes-Pérez, F.R.; Fernández-Quintanilla, C.; Dorado, J. The attractiveness of flowering herbaceous plants to bees (Hymenoptera: Apoidea) and hoverflies (Diptera: Syrphidae) in agro-ecosystems of central Spain. Agric. For. Entomol. 2014, 17, 20-28. [CrossRef]

18. R Core Team. R: A Language and Environment for Statistical Computing; R Foundation for Statistical Computing: Vienna, Austria, 2020.

19. Bates, D.; Mächler, M.; Bolker, B.M.; Walker, S.C. Fitting linear mixed-effects models using lme4. J. Stat. Softw. 2015, 67. [CrossRef]

20. Fox, J.; Weisberg, S. An R Companion to Applied Regression, 3rd ed.; Sage Publications: Thousand Oaks, CA, USA, 2019.

21. Barton, K. MuMIn: Multi-Model Inference. R Package Version 1.43.6. 2019. Available online: https://cran.r-project.org/web/ packages/MuMIn/ (accessed on 1 March 2021).

22. Nakagawa, S.; Johnson, P.C.D.; Schielzeth, H. The coefficient of determination R2 and intra-class correlation coefficient from generalized linear mixed-effects models revisited and expanded. J. R. Soc. Interface 2017, 14. [CrossRef]

23. Goode, K.; Rey, K. ggResidpanel: Panels and Interactive Versions of Diagnostic Plots Using 'ggplot2'. R Package Version 0.3.0. 2019. Available online: https:/ / cran.r-project.org/web/packages/ggResidpanel/ (accessed on 1 March 2021).

24. Russell, L. Emmeans: Estimated Marginal Means, aka Least-Squares Means. R Package Version 1.5.2-1. 2020. Available online: https:/ / cran.r-project.org/web/packages/emmeans/ (accessed on 1 March 2021).

25. Abrol, D.P. Factors influencing flight activity of Apis florea F, an important pollinator of Daucus carota L. J. Apic. Res. 2006, 45, 2-6. [CrossRef]

26. Lamborn, E.; Ollerton, J. Experimental assessment of the functional morphology of inflorescences of Daucus carota (Apiaceae): Testing the "fly catcher effect". Funct. Ecol. 2000, 14, 445-454. [CrossRef]

27. Pérez-Bañón, C.; Petanidou, T.; Marcos-García, M.Á. Pollination in small islands by occasional visitors: The case of Daucus carota subsp. commutatus (Apiaceae) in the Columbretes archipelago, Spain. Plant. Ecol. 2007, 192, 133-151. [CrossRef]

28. Wäckers, F.L. Assessing the suitability of flowering herbs as parasitoid food sources: Flower attractiveness and nectar accessibility. Biol. Control. 2004, 29, 307-314. [CrossRef]

29. Ahmad, M.; Aslam, M. Pollinators visiting carrot (Daucus carota L.) seed crop. J. Res. 2002, 13, 31-35.

30. Westmoreland, D.; Muntan, C. The influence of dark central florets on insect attraction and fruit production in Queen Anne's Lace (Daucus carota L.). Am. Midl. Nat. 1996, 135, 122-129. [CrossRef]

31. Clark, D.L.; Wilson, M.V. Post-dispersal seed fates of four prairie species. Am. J. Bot. 2003, 90, 730-735. [CrossRef] [PubMed]

32. Eckardt, N. Element Stewardship Abstract for Daucus carota; The Nature Conservancy: Arlington, VA, USA, 1987.

33. Mcnaughton, A.I.H.; Harper, J.L. Papaver L. J. Ecol. 1964, 52, 767-793. [CrossRef]

34. Bosch, J.; Retana, J.; Cerdá, X. Flowering phenology, floral traits and pollinator composition in a herbaceous Mediterranean plant community. Oecologia 1997, 109, 583-591. [CrossRef]

35. Hicks, D.M.; Ouvrard, P.; Baldock, K.C.R.; Baude, M.; Goddard, M.A.; Kunin, W.E.; Mitschunas, N.; Memmott, J.; Morse, H.; Nikolitsi, M.; et al. Food for pollinators: Quantifying the nectar and pollen resources of urban flower meadows. PLoS ONE 2016, 11, e0158117. [CrossRef]

36. Gashler, K. Native Bees are Better Pollinators, more Plentiful than Honeybees, Finds Entomologist. Available online: http: //news.cornell.edu/stories/2011/10/native-bees-are-better-pollinators-honeybees (accessed on 13 March 2018).

37. Mitich, L.W. Intriguing world of weeds: Corn Poppy (Papaver rhoeas L.). Weed Technol. 2000, 14, 826-829. [CrossRef]

38. Royal Botanic Garden Kew Science. Available online: https:/ /www.kew.org/science (accessed on 1 November 2018).

39. Plantwise Knowledge Bank. Available online: https:/ / www.plantwise.org/knowledgebank/home.aspx (accessed on 17 November 2017).

40. Dib, H.; Libourel, G.; Warlop, F. Entomological and functional role of floral strips in an organic apple orchard: Hymenopteran parasitoids as a case study. J. Insect Conserv. 2012, 16, 315-318. [CrossRef]

41. Carreck, N.L.; Williams, I.H. Observations on two commercial flower mixtures as food sources for beneficial insects in the UK. J. Agric. Sci. 1997, 128, 397-403. [CrossRef]

42. Carreck, N.; Williams, I. Food for insect pollinators on farmland: Insect visits to flowers of annual seed mixtures. J. Insect Conserv. 2002, 6, 13-23. [CrossRef]

43. Kühn, I.; Durka, W.; Klotz, S. BiolFlor-A new plant-trait database as a tool for plant invasion ecology. Divers. Distrib. 2004, 10, 363-365.

44. Gorenflo, A.; van Kleunen, M.; Wolters, V.; Jauker, F. Contrasting pollination efficiency and effectiveness among flower visitors of Malva sylvestris, Borago officinalis and Onobychis viciifolia. J. Pollinat. Ecol. 2017, 21, 62-70.

45. Gasparetto, J.C.; Martins, C.A.F.; Hayashi, S.S.; Otuky, M.F.; Pontarolo, R. Ethnobotanical and scientific aspects of Malva sylvestris L.: A millennial herbal medicine. J. Pharm. Pharmacol. 2012, 64, 172-189. [CrossRef]

46. Dutoit, T.; Buisson, E.; Gerbaud, E.; Roche, P.; Tatoni, T. The status of transitions between cultivated fields and their boundaries: Ecotones, ecoclines or edge effects? Acta Oecol. 2007, 31, 127-136. [CrossRef]

47. Mulligan, G.A.; Kevan, P.G. Color, brightness, and other floral characteristics attracting insects to the blossoms of some Canadian weeds. Can. J. Bot. 1973, 51, 1939-1952. [CrossRef]

48. Waddington, K.D. Foraging patterns of Halictid bees at flowers of Convolvulus arvensis. Psyche 1976, 83, 112-119. [CrossRef] 
49. Weaver, S.E.; Riley, W.R. The biology of Canadian weeds. 53. Convolvulus arvensis L. Can. J. Plant. Sci. 1982, 62, 461-472. [CrossRef]

50. Liebman, M.; Mohler, C.; Staver, C. Ecological Management of Agricultural Weeds; Cambridge University Press: Cambridge, UK, 2001; ISBN 0-521-56068-3.

51. Lusweti, A.; Wabuyele, E.; Ssegawa, P.; Mauremootoo, J. BioNET-EAFRINET keys and fact sheets, Convolvulus arvensis (Field Bindweed). Available online: https:/ / keyserver.lucidcentral.org (accessed on 20 November 2017).

52. Cox, H. The eradication of Bindweed, or Wild Morning-Glory; Government Printing Office: Washington, DC, USA, 1915.

53. Lewin, R. Sonchus L. J. Ecol. 1948, 36, 203-223. [CrossRef]

54. Percival, M.S. The presentation of pollen in certain angiosperms and its collection by Apis mellifera. New Phytol. 1955, 54, 353-368. [CrossRef]

55. Uva, R.H.; Neal, J.C.; DiTomaso, J.M. Weeds of the Northeast; Cornell University Press: Ithaca, NY, USA, 1997.

56. US Forest Service Pacific Island Ecosystems at Risk (PIER)-Sonchus oleraceus. Available online: http://www.hear.org/pier/ species/sonchus_oleraceus.htm (accessed on 20 November 2017).

57. Weber, E. Invasive Plants of the World; CABI Publishing: Wallingford, UK, 2003.

58. Altieri, M.; Nicholls, C. Biodiversity and Pest Management in Agroecosystems, 2nd ed.; CRC Press: Boca Raton, FL, USA, 2004.

59. Moisan-De Serres, J.; Bourgouin, F.; Lebeau, M.-O. Pollinisateurs et Plants Melliferes; CRAAQ: Quebec, QC, Canada, 2014; ISBN 9782764902486.

60. The Xerces Society. Attracting Native Pollinators: The Xerces Society Guide to Conserving North American Bees and Butterflies and Their Habitat; Burns, D., Ed.; Storey Publishing: North Adams, MA, USA, 2011; ISBN 978-1-60342-695-4.

61. Gillott, C. Entomology, 3rd ed.; Springer Science \& Business Media: Dordrecht, The Netherlands, 2005.

62. Arnett, R.H.; Thomas, M.C.; Skelley, P.E.; Frank, H.J. American Beetles; CRC Press: Boca Raton, FL, USA, 2002; Volume 2, ISBN 978-0849309540.

63. Davies, R.G. (Ed.) Outlines of Entomology, 7th ed.; Springer Science \& Business Media: London, UK, 2013 ; ISBN 9789400911895.

64. Wheeler, A.G. Biology of the Plant Bugs (Hemiptera: Miridae); Cornell University Press: Ithaca, NY, USA, 2001; ISBN1 0801438276. ISBN2 9780801438271.

65. Hodgson, E.W.; Patterson, R. Beneficial Insects: True Bugs; Utah State University: Logan, UT, USA, 2007.

66. Meyer, J. General Entomology, Hempiptera suborder Heteroptera. Available online: https://projects.ncsu.edu/cals/course/ent4 25/library/compendium/heteroptera.html (accessed on 24 November 2017).

67. Borges, P.; Reut, M.; Ponte, N.; Quartau, J.; Fletcher, A.; Pollet, M.; Soares, A.; Marcelino, J.; Rego, C.; Cardoso, P. New records of exotic spiders and insects to the Azores, and new data on recently introduced species. Arquipel. Life Mar. Sci. 2013, $30,57-70$.

68. Kalushkov, P.; Simov, N.; Tzankova, R. Laboratory and field investigations on the biology Oxycarenus lavaterae (Fabricus) (Heteroptera: Lygaeldae) in Bulgaria. Acta Zool. Bulg. 2007, 59, 217-219.

69. Shuker, D.M.; Ballantyne, G.A.; Wedell, N. Variation in the cost to females of the sexual conflict over mating in the seed bug, Lygaeus equestris. Anim. Behav. 2006, 72, 313-321. [CrossRef]

70. Bryant, P.J. Invasion of southern California by the Palearctic pyrrhocorid Scantius aegyptius (Hemiptera: Heteroptera: Pyrrhocoridae). Pan Pac. Entomol. 2009, 85, 190-193. [CrossRef]

71. Marshall, E.J.P. Agricultural landscapes: Field margin habitats and their interaction with crop production. J. Crop Improv. 2004, 12, 365-404. [CrossRef]

72. Altieri, M.A.; Farrell, J.G.; Hecht, S.B.; Liebman, M.; Magdoff, F.; Murphy, B.; Norgaard, R.B.; Sikor, T.O. Agroecology; CRC Press: Boca Raton, FL, USA, 2018; ISBN 9780429495465. 